\title{
Phenolic and Glycoside Compounds Obtained from Brucea antidysenterica
}

\author{
Tariku Nefo Duke \\ Department of Chemistry, College of Natural and Computational Sciences, University of Wolaita Sodo, P.O. \\ Box, 138, Ethiopia.
}

\begin{abstract}
Phenolic and glycoside compounds have been isolated from berries of Brucea antidysenterica. Based on spectroscopic data (IR, ${ }^{1} \mathrm{H}$ NMR, ${ }^{13} \mathrm{C}$ NMR and MS), the structure of phenolic compound D1 was identified as: 3-(3-hydroxybutyl)phenol $\left(\mathrm{C}_{10} \mathrm{H}_{14} \mathrm{O}_{2}\right)$ and glycoside compound $\mathrm{B} 6$ was identified as: ethyl 4-(3-(6-(tetrahydro3,4,5-trihydroxy-6-(hydroxymethyl)-2H-pyran-2-yloxy)hexyl)phenyl)butanoate $\left(\mathrm{C}_{24} \mathrm{H}_{38} \mathrm{O}_{8}\right)$.

Keywords: Phenolic; glycoside; Brucea antidysenterica; ${ }^{1} \mathrm{H}$ NMR

DOI: $10.7176 / \mathrm{CPER} / 60-01$

Publication date:March $31^{\text {st }} 2019$

\section{Introduction}

Almost 20 years ago the World Health Organization (WHO) estimated that 'In many countries, $80 \%$ or more of the population living in rural areas are cared for by traditional practitioners and birth attendants' [1]. It has since revised its view, adopting a rather safer position, now stating: 'most of the population of most developing countries regularly uses traditional medicine.' [2]. Natural products have a wide range of diversity of multi-dimensional chemical structures; in the meantime, the utility of natural products as biological function modifiers has also won considerable attention. Subsequently, they have been successfully employed in the discovery of new drugs and have exerted a far-reaching impact on chemicobiology [3-5]. From the past century, the high structural diversity of natural products has been realized from the perspective of physical chemistry. Their efficacy is related to the complexity of their well-organized three dimensional chemical and steric properties, which offer many advantages in terms of efficiency and selectivity of molecular targets. As a successful example of drug development from natural products, artemisinin and its analogs are presently in wide use for the anti-malaria treatment. This shows how research using natural products has made a significant contribution in drug development $[6,7]$.

Brucea is a genus of plant in the family Simaroubaceae, the family comprises medium sized family of about 25 genera and 120 species which are mainly small trees or shrubs, distributed widely in tropical America and West Africa [8]. The fruits, leaves and roots of Brucea antidysenterica are mixed with small amount of water and applied to treat wound [9]. Bruceantin (2) and analogues compounds are triterpenes of the quassinoid type isolated from the bark of the Ethiopian tree Brucea antidysenterica. They are capable of inducing an array of biological responses including anti-inflammatory effect with murine models [10]. Bruceantin (2) shows marked amoebicidal activity in vitro in the colony assay. At concentration of $0.2 \mu \mathrm{g} / \mathrm{ml}$ and above, all of the parasites Entamoeba histolytica (the dysentery amoeba) are killed. At $0.1 \mu \mathrm{g} / \mathrm{ml}$, few parasites survive at $48 \mathrm{~h}$, and all of the parasites are killed after $72 \mathrm{~h}$ to $0.1 \mu \mathrm{g} / \mathrm{ml}$ [11]. Brucea antidysenterica is one of the medicinal plants which are present at various geographical locations and their presumptive folklore used to prescribe for ascaris in the researcher areas.
\end{abstract}

\section{Materials and methods}

\section{Plant collection and identification}

The berries of Brucea antidysenterica were collected from southern nations, nationalities, and peoples' region of Ethiopia from Humbo woreda, which is around $347.5 \mathrm{~km}$, south of Addis Ababa. The plant was identified by botanist in the department of biology, Wolaita Sodo University.

\section{Extraction and isolation}

Compound D1, the air-dried berries of Brucea antidysenterica $(120 \mathrm{~g})$ were extracted with one liter of methanol. The $\mathrm{CH}_{3} \mathrm{OH}$ soluble crude $(4.5 \mathrm{~g})$ was chromatographed on silica gel $(190 \mathrm{~g})$ using gradient elution with $n$-hexane - EtOAc (10:0 to 0:10). Compound D1 (14 mg) was obtained from the $n$-hexane - EtOAc (1:9) fraction.

Compound B6, the air-dried berries of Brucea antidysenterica $(200 \mathrm{~g})$ were extracted with one liter of ethyl acetate. The $\mathrm{CHCl}_{3}$ soluble crude $(8 \mathrm{~g})$ was chromatographed on silica gel $(210 \mathrm{~g})$ using gradient elution with $\mathrm{MeOH}-\mathrm{CHCl}_{3}$ (10:0 to 3:7). Compound B6 (29.5 mg) yellowish solid was obtained from the $\mathrm{MeOH}-\mathrm{CHCl}_{3}$ (3: 7) fraction.

\section{Instruments}

${ }^{1} \mathrm{H}$ NMR $\left(400 \mathrm{MHz}\right.$, DMSO- $\left.d_{6}\right)$ and ${ }^{13} \mathrm{C}$ NMR $\left(100 \mathrm{MHz}\right.$, DMSO- $\left.d_{6}\right)$ spectra were recorded on a Bruker ARXNMR spectra and with TMS as an internal standard (chemical shifts in $\delta$, ppm). The isolated compounds were 
dissolved in DMSO- $d_{6}$ and analyzed with one-dimensional NMR (proton ${ }^{1} \mathrm{H}$, carbon ${ }^{13} \mathrm{C}$ ). An ESI-MASS/MS spectrum was recorded on an LC-MS mass spectrometer.

\section{Characterization of the compounds}

\section{Characterization of compound D1}

Compound D1 was obtained from methanol extract. Its molecular formula, $\mathrm{C}_{10} \mathrm{H}_{14} \mathrm{O}_{2}$ was determined by negative LC-MS. In the negative LC-MS spectrum, the quasi-molecular ion peak was at $\mathrm{m} / \mathrm{z} 166.56[\mathrm{M}-\mathrm{H}]$. In the IR $(\mathrm{KBr})$ spectrum the absorption band at $3435 \mathrm{~cm}^{-1}$ due to hydroxyl group and strong absorption band at $2923 \mathrm{~cm}^{-1}$ due to saturated C-H stretching.

The ${ }^{1} \mathrm{H}$ NMR spectrum exhibited signals for the presence of a benzene ring at $\delta_{\mathrm{H}} 7.14(1 \mathrm{H}, \mathrm{d}, \mathrm{d}), \delta_{\mathrm{H}} 6.98(1 \mathrm{H}, \mathrm{d})$, $\delta_{\mathrm{H}} 6.72(1 \mathrm{H}, \mathrm{d})$ and $\delta_{\mathrm{H}} 6.59(1 \mathrm{H})$. Signal at $2.88(2 \mathrm{H}, \mathrm{t})$ due to proton signal of methylene connected to phenyl), while, the $\delta_{\mathrm{H}} 3.49(1 \mathrm{H}, \mathrm{t}$,) was assigned to the methine carbon bearing alcohol.

In the ${ }^{13} \mathrm{C}$ NMR spectrum, there were ten carbon signals and signals at $\delta_{\mathrm{C}} 142, \delta_{\mathrm{C}} 132, \delta_{\mathrm{C}} 118.8, \delta_{\mathrm{C}} 122, \delta_{\mathrm{C}} 118.5$ and $\delta_{\mathrm{C}} 158.2$ each of which almost certainly carbon atoms ( $44, \mathrm{C} 2, \mathrm{C} 1, \mathrm{C} 3, \mathrm{C} 5$ and $\left.\mathrm{C} 6\right)$ assigned for phenol ring. Signals at $\delta_{C} 68.5$ assigned for secondary alcohol. (Table 1)

All chemical shift data in the 1D-NMR, IR and LC-MS spectra closely matched the tentative proposed structure for the compound D1 [3-(3-hydroxybutyl)phenol]. (See fig 1)

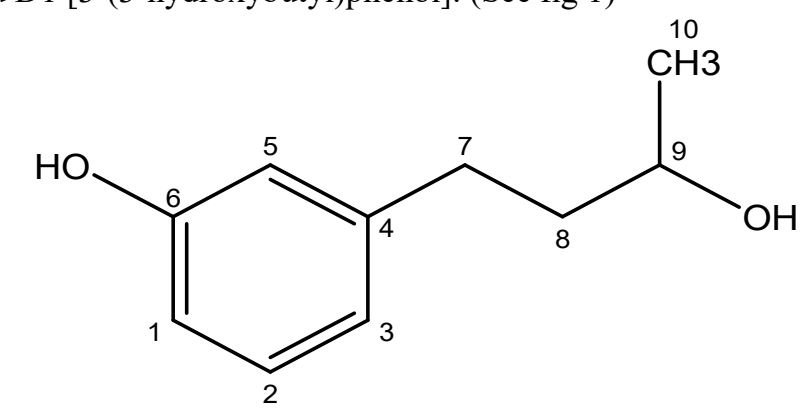

Fig. 1 The structure of compound D1

Table $1{ }^{1} \mathrm{H}$ NMR, ${ }^{13} \mathrm{C}$ NMR and DEPT-135 spectral data of D1 in DMSO- $d_{6}$

$\begin{array}{cccc}\text { Position } & { }^{1} \mathrm{H} \mathrm{NMR}(\mathrm{ppm}) & { }^{13} \mathrm{C} \mathrm{NMR}(\mathrm{ppm}) & \text { DEPT-135 } \\ 1 & 6.72(1 \mathrm{H}, \mathrm{d}) & 118.8 & \mathrm{CH} \\ 2 & 7.14(1 \mathrm{H}, \mathrm{d}, \mathrm{d}) & 132 & \mathrm{CH} \\ 3 & 6.98(1 \mathrm{H}, \mathrm{d}) & 122 & \mathrm{CH} \\ 4 & & 142 & \text { Quaternary } \\ 5 & 6.59(1 \mathrm{H}, \mathrm{d}) & 118.5 & \mathrm{CH} \\ 6 & & 158.2 & \text { Quaternary } \\ 7 & 2.55(2 \mathrm{H},) & 30 & \mathrm{CH}_{2} \\ 8 & 2.88(2 \mathrm{H}, \mathrm{d}, \mathrm{t}) & 42 & \mathrm{CH}_{2} \\ 9 & 3.49(1 \mathrm{H}, \mathrm{m}) & 68.5 & \mathrm{CH} \\ 10 & 1.22(3 \mathrm{H}, \mathrm{d}) & 24.2 & \mathrm{CH}_{3}\end{array}$

\section{Characterization of compound B6}

Compound B6 was obtained as a dark solid from ethyl acetate (EtOAc) extract. Its molecular formula, $\mathrm{C}_{24} \mathrm{H}_{38} \mathrm{O}_{8}$ was determined by negative LC-MS. In the negative LC-MS spectrum, the quasi-molecular ion peak was at $\mathrm{m} / \mathrm{z}$ $455.06[\mathrm{M}-\mathrm{H}]^{-}$.

In the IR (KBr) spectrum the strong absorption band at $2924 \mathrm{~cm}^{-1}$ is due to saturated $\mathrm{C}-\mathrm{H}$ stretching and medium intensity band at $1466 \mathrm{~cm}^{-1}$ due to $-\mathrm{CH}_{2}-$ bend. Strong absorption band at $1745 \mathrm{~cm}^{-1}$ shows ester group and absorption band at $1167 \mathrm{~cm}^{-1}$ due to $\mathrm{C}-\mathrm{O}$ stretching.

The ${ }^{1} \mathrm{H}$ NMR spectrum exhibited signals for the presence of a benzene ring at $\delta_{\mathrm{H}} 6.95(1 \mathrm{H}), \delta_{\mathrm{H}} 7.16(1 \mathrm{H}, \mathrm{d}, \mathrm{d})$, $\delta_{\mathrm{H}} 6.98(1 \mathrm{H}, \mathrm{d})$ and $\delta_{\mathrm{H}} 6.94(1 \mathrm{H}, \mathrm{d}, \mathrm{d})$. Signal at $4.19(2 \mathrm{H}, \mathrm{q}$, the proton signal of methylene connected to an oxygen atom), while, the $\delta_{\mathrm{H}} 4.9(1 \mathrm{H}, \mathrm{d}, J=7.8 \mathrm{~Hz})$ was assigned to the anomeric proton of sugar.

In the ${ }^{13} \mathrm{C}$ NMR spectrum, there were twenty-four carbon signals and signals at $\delta_{\mathrm{C}} 134.34, \delta_{\mathrm{C}} 128.4, \delta_{\mathrm{C}} 130.35$, $\delta_{\mathrm{C}} 125.4, \delta_{\mathrm{C}} 128.5$ and $\delta_{\mathrm{C}} 129.2$ each of which almost certainly carbon atoms ( $33, \mathrm{C} 5, \mathrm{C} 4, \mathrm{C} 6, \mathrm{C} 2$ and $\left.\mathrm{C} 1\right)$ assigned for aromatic ring. Signals at $\delta_{\mathrm{C}} 174.9$ showed there was an ester carbonyl group. In addition the signals at $\delta_{\mathrm{C}} 95.5$, $76.7,73,72.2,69.2$ and 60.3 were assigned to the sugar part. (Table 2)

All chemical shift data in the 1D-NMR, IR and LC-MS spectra closely matched the tentative proposed structure for the compound B6 [Ethyl 4-(3-(6-(tetrahydro-3,4,5-trihydroxy-6-(hydroxymethyl)-2H-pyran-2yloxy)hexyl)phenyl)butanoate]. (See fig 2) 
<smiles>CCOC(=O)CCCc1cccc(CCCCCCOC2O[C@H](C(=O)O)C(O)C(O)C2O)c1</smiles>

Fig. 2 The structure of compound B6

Table $2{ }^{1} \mathrm{H}$ NMR, ${ }^{13} \mathrm{C}$ NMR and DEPT-135 spectral data of B6 in DMSO- $d_{6}$

\begin{tabular}{|c|c|c|c|}
\hline Position & ${ }^{1} \mathrm{H}$ NMR (ppm) & ${ }^{13} \mathrm{C}$ NMR(ppm) & DEPT-135 \\
\hline 1 & $7.16(1 \mathrm{H}, \mathrm{d}, \mathrm{d})$ & 129.2 & $\mathrm{CH}$ \\
\hline 2 & $6.95(1 \mathrm{H}, \mathrm{d} J=8.4 \mathrm{~Hz})$, & 128.5 & $\mathrm{CH}$ \\
\hline 3 & & 134.4 & Quaternary \\
\hline 4 & $6.98(1 \mathrm{H})$ & 130.35 & $\mathrm{CH}$ \\
\hline 5 & & 128.4 & Quaternary \\
\hline 6 & $6.94(1 \mathrm{H}, \mathrm{d})$ & 125.4 & $\mathrm{CH}$ \\
\hline 7 & $2.55(2 \mathrm{H}$, overlapped $)$ & 35.7 & $\mathrm{CH}_{2}$ \\
\hline 8 & $2.01(2 \mathrm{H}, \mathrm{t}, \mathrm{t} J=5.7 \mathrm{~Hz})$ & 24.83 & $\mathrm{CH}_{2}$ \\
\hline 9 & $2.25(2 \mathrm{H}, \mathrm{t})$ & 32.18 & $\mathrm{CH}_{2}$ \\
\hline 10 & & 174.95 & Quaternary \\
\hline 11 & $2.55(2 \mathrm{H}$, overlapped $)$ & 34.25 & $\mathrm{CH}_{2}$ \\
\hline 12 & $1.62(2 \mathrm{H}, \mathrm{t}, \mathrm{t})$ & 29.46 & $\mathrm{CH}_{2}$ \\
\hline 13 & $1.29(2 \mathrm{H}, \mathrm{t}, \mathrm{t} J=4 \mathrm{~Hz})$ & 28.65 & $\mathrm{CH}_{2}$ \\
\hline 14 & $1.29(2 \mathrm{H}, \mathrm{t}, \mathrm{t})$ & 23.57 & $\mathrm{CH}_{2}$ \\
\hline 15 & $1.40(2 \mathrm{H}, \mathrm{t}, \mathrm{t})$ & 29.57 & $\mathrm{CH}_{2}$ \\
\hline 16 & $3.37(2 \mathrm{H}, \mathrm{t})$ & 65 & $\mathrm{CH}_{2}$ \\
\hline \multicolumn{4}{|l|}{17} \\
\hline 18 & $4.9(1 \mathrm{H}, \mathrm{d}, J=7.8 \mathrm{~Hz})$ & 95.5 & $\mathrm{CH}$ \\
\hline 19 & $3.73(1 \mathrm{H}, \mathrm{m})$ & 72.2 & $\mathrm{CH}$ \\
\hline 20 & $3.49(1 \mathrm{H}, \mathrm{d}, \mathrm{d})$ & 73 & $\mathrm{CH}$ \\
\hline 21 & $3.4(1 \mathrm{H}, \mathrm{d}, \mathrm{d})$ & 69.2 & $\mathrm{CH}$ \\
\hline 22 & $3.76(1 \mathrm{H}, \mathrm{d}, \mathrm{t})$ & 75.7 & $\mathrm{CH}$ \\
\hline \multicolumn{4}{|l|}{23} \\
\hline 24 & $3.62(2 \mathrm{H}, \mathrm{d}, \mathrm{d})$ & 59.4 & $\mathrm{CH}_{2}$ \\
\hline \multicolumn{4}{|c|}{$.02(211, \mathrm{a}, \mathrm{a})$} \\
\hline 26 & $4.19(2 \mathrm{H}, \mathrm{q})$ & 76 & $\mathrm{CH}_{2}$ \\
\hline 27 & $1.3(3 \mathrm{H}, \mathrm{t})$ & 14.28 & $\mathrm{CH}_{3}$ \\
\hline
\end{tabular}

\section{Conclusion and recommendations}

This work has demonstrated that the berries of Brucea antidysenterica are rich sources of different compounds and resulted in the isolation of phenolic compound it were identified as D1: 3-(3-hydroxybutyl) phenol and glycoside compound B6: ethyl 4-(3-(6-(tetrahydro-3,4,5-trihydroxy-6-(hydroxymethyl)-2H-pyran-2 yloxy) hexyl)phenyl) butanoate. The structures of the compounds were characterized on the basis of spectral data $\left({ }^{1} \mathrm{H}\right.$ NMR, ${ }^{13} \mathrm{C}$ NMR, DEPT-135, IR and LC-MS) as well as comparison with the literature data. Based on TLC analysis the plant contains several polar chemical constituents which were not isolated in this study because of time constraints. It is possible to isolate more polar compounds using advanced chromatographic techniques. Therefore, much more phytochemical and biological study should be carried out on the plant in future. 


\section{Acknowledgement}

Author like to acknowledge Wolaita Sodo University for providing grant and laboratory equipment for this project.

\section{References}

[1] Bannerman RH.Traditional Medicine and Healthcare Coverage. Geneva: World Health Organization, 1983.

[2] World Health Organization. Traditional Medicine. WHO Fact Sheet No. 134. Geneva: WHO, revised 2003. Available at: http://tinyurl.com/5mrd5 (accessed 11 December 2008).

[3] Hong, J.Y. Natural product diversity and its role in chemical biology and drug discovery. Curr. Opin. Chem. Biol. 2011, 15, 350-354.

[4] Rosén, J.; Gottfries, J.; Muresan, S.; Backlund, A.; Oprea, T.I. Novel chemical space exploration via natural products. J. Med. Chem. 2009, 52, 1953-1962. [Cross Ref] [Pub Med]

[5] Butler, M.S. Natural products to drugs: Natural product-derived compounds in clinical trials. Nat. Prod. Rep. 2008, 25, 475-516.

[6] Muschietti, L.; Vila, R.; Filho, V.C.; Setzer, W. Tropical Protozoan Diseases: Natural Product Drug Discovery and Development. Evid. Based Complement. Altern. Med. 2013, 2013.

[7] Cragg, G.M.; Newman, D.J. Natural products: A continuing source of novel drug leads. Biochim. Biophys. Acta 2013, 1830, 3670-3695. [Cross Ref] [Pub Med]

[8] Hedberg, I., Edvans, S., 1989. Simaroubaceae. Flora of Ethiopia 3. Uppsala, 437- 441.

[9] Mesfin, T., 1986. Some Medicinal Plants of Central Shewa and South Western Ethiopia. Sinet: Ethiopia. J. Sci. 9 (suppl.), 143-167.

[10] Kupchan, S. M., Britton, W. R., Lacadie, J. A., Ziegler, M. F., Sigel, C. W., 1973. Bruceantin a New Potent Antileukemic Simaroubolide from Brucea antidysenterica. J. Org. Chem. 38, 178-179.

[11] Frances, D. G., David, S. R., Matthew, S., 1982. Bruceantin, a Potent Amoebicide from a Plant, Brucea antidysenterica. Antimicrobial Agents and Chemotherapy. 22, 342-345. 